\title{
Effects of erythropoietin on advanced pulmonary vascular remodelling
}

\author{
M.E. van Albada*, G.J. du Marchie Sarvaas*, J. Koster", M.C. Houwertjes ${ }^{\star}$, \\ R.M.F. Berger*, ${ }^{*}$ and R.G. Schoemaker ${ }^{+}$
}

ABSTRACT: Erythropoietin (EPO) mobilises endothelial progenitor cells and promotes neovascularisation in heart failure. The present authors studied the effects of EPO on pulmonary vascular and cardiac remodelling in a model for flow-associated pulmonary arterial hypertension (PAH).

PAH was induced in adult male Wistar rats by the injection of monocrotaline combined with an abdominal aortocaval shunt 1 week later (PAH or experimental group). Immediately afterwards, rats were randomised into those who received treatment with EPO (PAH+EPO group) and controls. Pulmonary and systemic haemodynamics, and right ventricular and pulmonary vascular remodelling were evaluated 3 weeks later.

Vascular occlusion of the intra-acinar pulmonary vessels $(13.4 \pm 0.7$ versus $16.7 \pm 1.3 \%$ in $\mathrm{PAH}+\mathrm{EPO}$ and PAH, respectively) and medial wall thickness of the pre-acinar arteries (wall-tolumen ratio $0.13 \pm 0.01$ versus $0.17 \pm 0.01$ in $\mathrm{PAH}+\mathrm{EPO}$ and $\mathrm{PAH}$, respectively) decreased after treatment with EPO. Moreover, right ventricular capillary density was increased by therapy $\left(2,322 \pm 61\right.$ versus $2,100 \pm 63$ capillaries $\cdot \mathrm{mm}^{-2}$ in $\mathrm{PAH}+\mathrm{EPO}$ and $\mathrm{PAH}$, respectively). Increased mean pulmonary arterial pressure and decreased right ventricular contractility in the model were not altered by EPO treatment.

In this rat model of flow-associated pulmonary arterial hypertension, erythropoietin treatment beneficially affected pulmonary vascular and cardiac remodelling. These histopathological effects were not accompanied by significantly improved haemodynamics.

KEYWORDS: Heart failure, histopathology, pulmonary circulation, ventricular function

rythropoietin (EPO) is best known for its role in haematopoiesis as a hypoxiainduced hormone that leads to the proliferation and differentiation of erythroid precursor cells. More recently, EPO has been shown to exert pleiotropic effects. It displays cytoprotective properties in acute brain and cardiac ischaemia associated with inhibition of apoptosis [1-4]. Furthermore, it has been demonstrated that improved cardiac function after EPO treatment is associated with the formation of new vessels in experimental heart failure [5].

Pulmonary arterial hypertension (PAH) is a disease in which pulmonary vascular remodelling leads to increased pulmonary vascular resistance (PVR) and, consequently, to right ventricular failure. EPO administration in the hypoxic rat model for pulmonary hypertension reduces pulmonary vascular remodelling, without effects on right ventricular hypertrophy or pulmonary pressures [6]. Furthermore, transgenic mice with increased EPO production appeared to be less sensitive to the development of hypoxic pulmonary hypertension [7]. In a recent study, mice lacking the EPO receptor had an accelerated development of pulmonary hypertension under hypoxic conditions, with more pronounced pulmonary vascular remodelling [8].

Hence, EPO may play an important role at multiple levels in the development of pulmonary vascular disease in PAH. EPO treatment could have beneficial effects in pulmonary hypertension either by improving capillarisation of the hypertrophied myocardium or by direct favourable effects on pulmonary vascular remodelling. Therefore, the present study was designed to determine the effects of EPO therapy on cardiac and pulmonary vascular remodelling in a rat model for flow-associated PAH.

\section{METHODS}

\section{Animals and study design}

In total, 45 male Wistar rats, weighing 315-370 g, were obtained from Harlan (Zeist, the Netherlands). The experimental protocol was approved by the institutional Animal Care and
AFFILIATIONS

*Dept of Paediatrics, Division of

Paediatric Cardiology, Beatrix

Children's Hospital, and

Depts of ${ }^{\#}$ Cardiology,

"Anaesthesiology, and

+Experimental Cardiology, University

Medical Center Groningen, University

of Groningen, Groningen, The

Netherlands.

\section{CORRESPONDENCE}

M.E. van Albada

Beatrix Children's Hospital

University Medical Center Groningen

Postbus 30.001

9700 RB Groningen

The Netherlands

Fax: 31503614235

E-mail: m.e.van.albada@bkk.umcg.nl

Received:

March 262007

Accepted after revision:

September 102007

STATEMENT OF INTEREST

None declared. 
Use Committee (University Medical Centre Groningen, Groningen, the Netherlands). The investigation conforms to the US National Institutes of Health "Guide for the Care and Use of Laboratory Animals" [9].

Rats were randomly assigned to three experimental groups as follows. 1) An experimental group (PAH group; $n=14$ ) in which flow-associated pulmonary hypertension was created as previously described elsewhere [10]. In brief, rats were subjected to a monocrotaline injection to increase pulmonary arterial pressure $\left(60 \mathrm{mg} \cdot \mathrm{kg}^{-1}\right.$; Sigma Chemical Co., St Louis, $\mathrm{MO}$, USA), followed by induction of increased flow through the creation of an abdominal aortocaval shunt 1 week later. 2) An experimental group that received treatment with EPO $\left(10 \mu \mathrm{g} \cdot \mathrm{kg}^{-1}\right.$ with a half-life of $\sim 50 \mathrm{~h}$, Darbepoetin- $\alpha$, Aranesp ${ }_{\mathbb{B}}$; Amgen Inc., Thousand Oaks, CA, USA) via a single intraperitoneal injection on the day of the abdominal surgery (PAH+EPO group; $n=18$ ). The dosage was chosen based on pilot experiments in the present authors' laboratory showing a significant rise in haematocrit, and is comparable to a dosage of $2,000 \mathrm{IU} \cdot \mathrm{kg}^{-1}$ of short-acting erythropoietin. 3) Rats that were subjected to sham surgery and saline injections served as controls $(n=13)$.

\section{Haemodynamic measurements}

Animals were anaesthetised with isoflurane $(2.0 \%)$ in a $2: 1$ mixture of nitrous oxide and oxygen 3 weeks after EPO administration. Pulmonary arterial pressures were measured using standard techniques routinely used in the present authors' laboratory [10], as described by RABINOVITCH [11]. If pulmonary arterial pressure could not be obtained, right ventricular systolic pressure (RVSP) was recorded as systolic pulmonary arterial pressure. Subsequently, a Microtip pressure transducer (Millar Instr. Inc., Houston, TX, USA) was inserted into the right ventricular cavity to determine RVSP and right ventricular end-diastolic pressure (RVEDP). As an index of contractility, the maximal rate of increase in right ventricular pressure (RVP; calculated as the variation of pressure $(P)$ with time $(t)$, i.e. $\mathrm{d} P / \mathrm{d} t \max )$ was taken and corrected for RVSP $(\mathrm{d} P / \mathrm{d} t \max$ index). Similarly, $-\mathrm{d} P / \mathrm{d} t \max$ index was calculated from the maximal rate of decrease in RVP and taken as the index for relaxation.

By introducing a catheter via the left carotid artery into the aorta, systemic arterial pressures, as well as cardiac frequency, were measured.

\section{Pulmonary vascular remodelling}

After completion of haemodynamic measurements, blood samples were drawn from the upper abdominal aorta and caval vein, and oxygen saturation was determined to calculate the aortocaval saturation difference. The thorax was opened and the heart and lungs were excised. The left lung was fixated by filling the airways with $3.6 \%$ formalin at a pressure of $20 \mathrm{cmH}_{2} \mathrm{O}$. The right lung was frozen in liquid nitrogen for further molecular analysis. Pulmonary sections (5- $\mu \mathrm{m}$ thick) were stained with haematoxylin and eosin and Verhoef elastin stain for morphometric analysis of vascular dimensions, according to a previously described protocol [10]. In lung sections, all transversally cut arteries with a diameter $\geqslant 50 \mu \mathrm{m}$ (pre-acinar arteries) and 40 randomly chosen vessels (10 in each left lung quadrant) with a diameter $<50 \mu \mathrm{m}$ (intra-acinar vessels) were quantitatively analysed at $200 \times$ and $400 \times$ magnification using an image analysis system (Image-Pro Plus 4.5; Media Cybernetics, Silver Spring, MD, USA) [10]. Vessels of $<50 \mu \mathrm{m}$ diameter usually do not have a clearly discernible internal elastic lamina. Therefore, a vascular occlusion score was calculated in these vessels, as opposed to the calculation of a medial wall/lumen ratio in the larger pulmonary arteries. Occlusion was calculated in the intra-acinar pulmonary vessels according to the following formula:

(outer vessel area-luminal area)/(outer vessel area)

Pulmonary arteries were excluded from measurement if they had a longest/shortest diameter of $>2$, an incomplete circular shape or a collapse of more than one quarter of the vessel wall. Muscularisation of 40 small pulmonary vessels was assessed according to VAN SUYLEN et al. [12]. A completely muscular vessel was defined as a vessel with a double elastic lamina for more than half the circumference. A vessel was categorised as partially muscular if the double elastic lamina was less than half the circumference. A nonmuscular vessel had a single elastic lamina.

\section{Right ventricular remodelling}

The heart was divided into atria, ventricles and septum. Sections were weighed separately and fixed in 3.6\% formalin. De-paraffinised 5 - $\mu \mathrm{m}$ thick transverse cardiac sections at midventricular level were stained with Gomori silver staining for analysis of myocyte size, and with Griffonia simplicifolia lectin staining (Sigma Chemical Co.) of endothelial cells for analysis of capillary density $[13,14]$. Image analysis (Image-Pro Plus 4.5) was used to measure capillary density and myocyte size. Capillary density was expressed as the number of capillaries per tissue area (capillaries $\cdot \mathrm{mm}^{-2}$ ) and myocyte size as the average cross-sectional area of transversally cut myocytes at the level of the nucleus.

\section{Gene expression}

In order to determine the expression of myosin-heavy chain (MHC) mRNA and of angiogenic factors, RNA was extracted from pulmonary and right ventricular tissue using the Qiagen RNEasy Mini Kit (Qiagen, Frankfurt, Germany). Real-time PCR experiments were performed on a Gene Amp 5700 Sequence detector (Applied Biosystems, Nieuwerkerk a/d IJssel, the Netherlands) as described previously [15]. Primers were designed for vascular endothelial growth factor (VEGF), its two receptor (R) subtypes VEGF-R1 and -R2, and for $\alpha$ - and $\beta$-MHC. Respective primer sequences are provided in table 1 . PCR results were obtained from a dilution standard curve.

\section{Statistical analysis}

Data are presented as mean \pm SEM. Group differences were analysed using one-way ANOVA testing with Fisher's protected least significant difference post hoc testing. The nonparametric Kruskall-Wallis test was used when data were not normally distributed, followed by Mann-Whitney post hoc testing with Bonferroni correction. Correlation analysis was performed with Pearson's correlation test. An $\alpha$-value of 0.05 was selected. 


\begin{tabular}{|c|c|}
\hline TABLE 1 & $\begin{array}{l}\text { Primer sequences for vascular endothelial } \\
\text { growth factor (VEGF) and its receptors (VEGF-R1 } \\
\text { and -R2), and } \alpha \text { - and } \beta \text {-myosin heavy chain } \\
\text { (MHC) }\end{array}$ \\
\hline Gene & Primer sequence \\
\hline \multirow[t]{2}{*}{ VEGF } & F 5'-GTACCTCCACCATGCCAAGT-3' \\
\hline & R 5'-AATAGCTGCGCTGGTAGACG-3' \\
\hline \multirow[t]{2}{*}{ VEGF-R1 } & F 5'-GACCTGCGAAGCCACAGTTA-3' \\
\hline & R 5'-GTCAATCCGCTGCCTGATAG-3' \\
\hline \multirow[t]{2}{*}{ VEGF-R2 } & F 5'-GCCTTATGATGCCAGCAAGT-3' \\
\hline & R 5'-GCCAATGTGGATGAGGATCT-3' \\
\hline \multirow[t]{2}{*}{$\alpha-\mathrm{MHC}$} & F 5'-GGCCAATAGAATAGCCTCCAG-3' \\
\hline & R 5'-TCCACGATGGGCGATGTTCTC-3' \\
\hline \multirow[t]{2}{*}{$\beta$-MHC } & F 5'-AGTGAAGAGCCTCCAGAGTT-3' \\
\hline & R 5'-TCCACGATGGGCGATGTTCTC-3' \\
\hline
\end{tabular}

\section{RESULTS}

\section{Animal model and treatment}

Shunt surgery was performed successfully in all but five of the 45 rats. Three animals died due to acute surgery-related complications; two animals did not have a shunt at the end of the protocol and, therefore, were excluded from further analysis. One rat in the EPO group died prematurely of unknown causes.

At the end of the protocol, experimental animals had decreased body weights and developed dyspnoea, defined as

\begin{tabular}{|c|c|c|c|}
\hline & CON & РAH & $\mathrm{PAH}+\mathrm{EPO}$ \\
\hline Body weight g & $398 \pm 6$ & $371 \pm 6^{\#}$ & $369 \pm 6^{\#}$ \\
\hline $\begin{array}{l}\text { Arterio-venous saturation } \\
\text { difference \% }\end{array}$ & $23.2 \pm 2.8$ & $6.4 \pm 1.0^{\#}$ & $6.5 \pm 2.1^{\#}$ \\
\hline \multicolumn{4}{|l|}{ Haemodynamics } \\
\hline $\begin{array}{l}\text { Mean pulmonary arterial pressure } \\
\mathrm{mmHg}\end{array}$ & $20 \pm 1$ & $41 \pm 2^{\#}$ & $40 \pm 2^{\#}$ \\
\hline $\mathrm{RV}$ end-diastolic pressure $\mathrm{mmHg}$ & $3.1 \pm 0.7$ & $6.2 \pm 1.0^{\#}$ & $7.0 \pm 1.5^{\#}$ \\
\hline $\mathrm{d} P / \mathrm{d} t$ max index & $97 \pm 8$ & $71 \pm 2^{\#}$ & $77 \pm 3^{\#}$ \\
\hline$-d P / d t m a x$ index & $86 \pm 6$ & $73 \pm 2^{\#}$ & $72 \pm 2^{\#}$ \\
\hline $\begin{array}{l}\text { Mean systemic arterial pressure } \\
\mathrm{mmHg}\end{array}$ & $111 \pm 5$ & $83 \pm 5^{\#}$ & $91 \pm 6^{\#}$ \\
\hline Cardiac frequency bpm & $384 \pm 10$ & $309 \pm 13^{\#}$ & $351 \pm 11^{\circ}$ \\
\hline \multicolumn{4}{|l|}{ Pathology } \\
\hline Heart/body weight ratio $\mathrm{g} \cdot \mathrm{kg}^{-1}$ & $2.77 \pm 0.05$ & $4.19 \pm 0.12^{\#}$ & $4.10 \pm 0.13^{\#}$ \\
\hline RV hypertrophy RV/(LV+IVS) & $0.25 \pm 0.01$ & $0.44 \pm 0.02^{\#}$ & $0.43 \pm 0.01^{\#}$ \\
\hline
\end{tabular}

Data are presented as mean \pm SEM. CON: controls; PAH: pulmonary arterial hypertension experimental group; PAH+EPO: PAH experimental animals treated with erythropietin; RV: right ventricle; (-)dP/dtmax index: maximal rate of (decrease) increase in right ventricular pressure (calculated as the variation of pressure $(P)$ with time $(t))$ corrected for right ventricular systolic pressure; bpm: beats per minute; LV: left ventricle; IVS: interventricular septum. ${ }^{*}$ : $p<0.05$ versus CON; ${ }^{\bullet}: p<0.05$ versus $\mathrm{PAH}$. the use of accessory respiratory muscles. EPO treatment did not alter body weight (table 2). Haematocrit was not significantly increased in the EPO-treated group 3 weeks after administration $(0.42 \pm 0.02$ versus $0.39 \pm 0.02$ in the $\mathrm{PAH}$ animals; $\mathrm{p}=0.41)$.

\section{Haemodynamics and cardiac function}

The aortocaval saturation difference was decreased in the shunted animal groups but remained identical between treated and untreated animals (table 2), indicating that there was no effect of treatment on shunt flow. Mean pulmonary arterial pressure and RVP were significantly increased in the experimental rats compared with controls. RVEDP was also increased compared with controls. Systemic arterial pressure and cardiac frequency decreased in the animal model. Treatment with EPO did not significantly alter pulmonary or systemic arterial pressures, nor did it change RVPs. Cardiac frequency increased significantly after EPO treatment (table 2). Myocardial contractility, measured as $\mathrm{d} P / \mathrm{d} t \max$ index, was impaired in the model. EPO treatment was not able to restore this impaired contractility. Similarly, impaired right ventricular relaxation was not altered after EPO treatment (table 2).

\section{Cardiac and pulmonary weights}

Experimental rats showed increased cardiac weights, as demonstrated by an increased organ weight/body weight ratio (table 2). Treatment with EPO did not alter total heart weight/body weight ratios. Right ventricular hypertrophy, expressed as right ventricular/left ventricular plus septal weight ratio, almost doubled in the untreated pulmonary hypertensive group, while EPO did not significantly influence this ratio (table 2 ).

\section{Pulmonary vascular remodelling}

Pre-acinar pulmonary arteries $(>50 \mu \mathrm{m})$

Representative pictures of pulmonary vascular remodelling are shown in figure 1. In the untreated rats, the pre-acinar pulmonary arteries had an increased wall thickness and wall/ lumen ratio and they increased in number in these animals. No intimal proliferation was observed in the pre-acinar arteries of the experimental animals. Treatment significantly reduced wall thickness in these arteries (table 3). The increased wall/ lumen ratio decreased by $>50 \%$ (figs $1 \mathrm{a}-\mathrm{c}$ and $2 \mathrm{a}$ ).

\section{Intra-acinar pulmonary vessels $(<50 \mu \mathrm{m})$}

The intra-acinar pulmonary vessels in the PAH group showed a decreased luminal diameter. Outer diameter remained similar to controls, indicating inward remodelling. Increased wall thicknesses, wall/lumen ratios and increased occlusion with more muscularisation support this observation. Therapeutic intervention with EPO decreased wall thickness (table 3) and occlusion scores (fig. 2b), but did not affect the degree of muscularisation (figs $1 \mathrm{~d}-\mathrm{f}$ and $2 \mathrm{c}$ ).

\section{Cardiac remodelling}

Right ventricular hypertrophy was further examined by determination of myocyte size. Myocyte cross-sectional area increased by $50 \%$ in the PAH group. Treatment did not result in a significant decrease in myocyte size (fig. 3a).

Capillaries stained with lectin could be discriminated clearly within the myocardium and representative examples from 

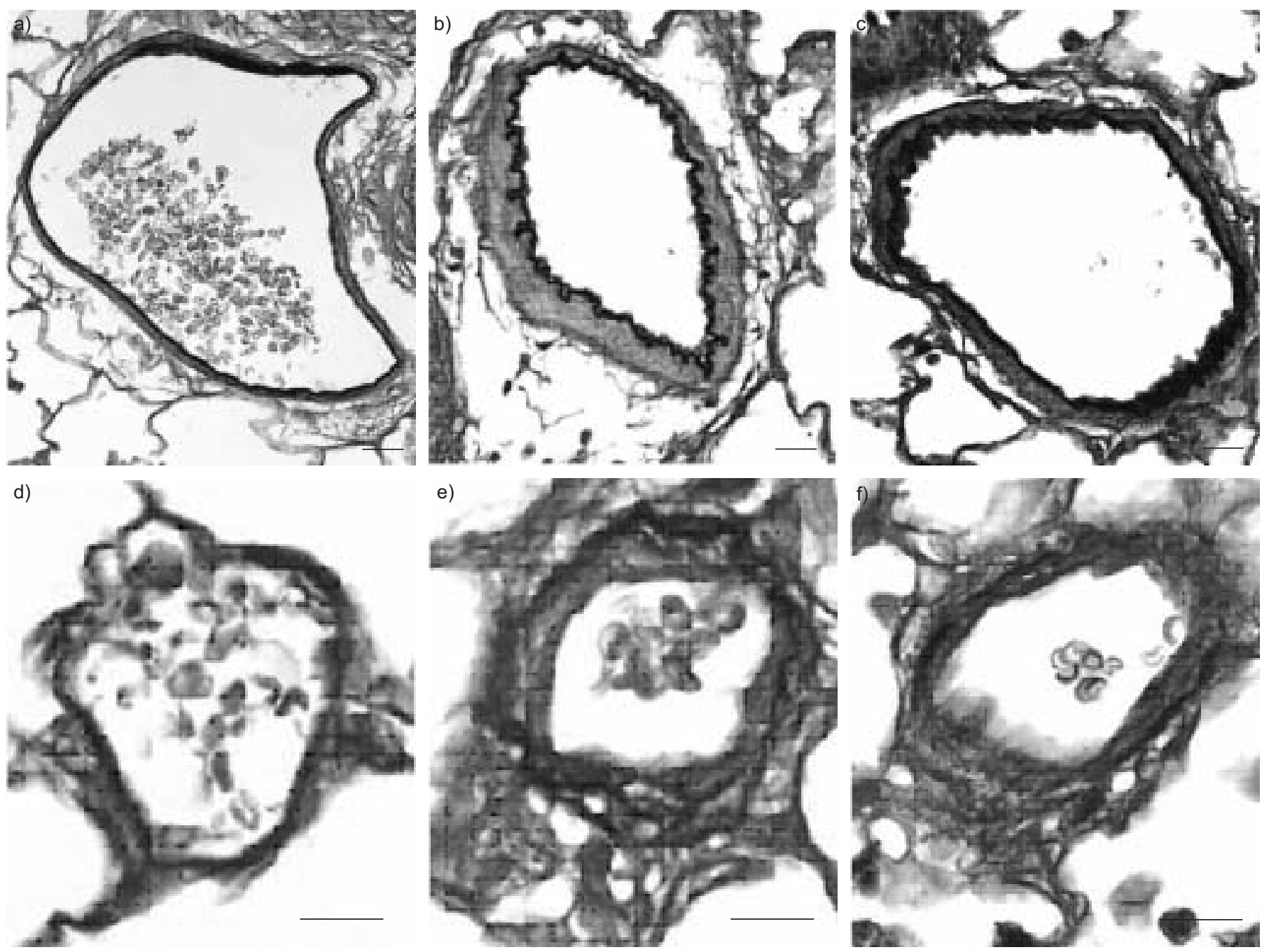

FIGURE 1. Typical examples of pulmonary histopathology (Verhoef elastin stain) in a-c) pre-acinar pulmonary arteries and d-f) intra-acinar pulmonary vessels of controls ( $a$ and $d$ ), experimental group ( $b$ and $e$ ) and experimental animals treated with erythropoietin (c and $f$ ). $a-c$ ) Scale bars $=20 \mu m, d-f$ ) Scale bars $=40 \mu m$.

each group are shown in figure 3c-e. Capillary density was decreased in the experimental group compared with controls $(2,100 \pm 63$ versus $2,891 \pm 110, \mathrm{p}<0.001$ versus controls $)$. Capillary density increased by $11 \%$ after EPO treatment $(2,322 \pm 61, \mathrm{p}=0.049$ versus the experimental group; fig. $3 b)$.

\section{GENE EXPRESSION}

Right ventricular expression of VEGF-R1 increased in the model, whereas VEGF and VEGF-R2 expressions did not change. Cardiac VEGF and VEGF-R2 expressions remained unaltered after treatment. However, therapy partially prevented the increase in VEGF-R1 expression in the untreated group (fig. 4a).

Pulmonary VEGF expression was not altered in the animal model, even after EPO treatment. Both VEGF-R1 and -R2 decreased in pulmonary tissue in the present model. EPO treatment restored pulmonary VEGF-R2 expression to nearnormal levels (fig. 4b), without affecting VEGF-R1 expression.

Right ventricular $\alpha$-MHC expression decreased in the model $(0.65 \pm 0.08$ versus $1.27 \pm 0.08$ in controls, $\mathrm{p}<0.001)$ but was not altered by therapy $(0.65 \pm 0.09, \mathrm{p}=$ nonsignificant (NS) versus $\mathrm{PAH}$ group). $\beta$-MHC expression increased in the animal model $(0.90 \pm 0.05$ versus $0.31 \pm 0.06$ in controls, $\mathrm{p}<0.001)$. Therapy did not influence this $(1.00 \pm 0.13, \mathrm{p}=\mathrm{NS}$ versus $\mathrm{PAH}$ group). Consequently, the ratio of $\beta / \alpha-\mathrm{MHC}$ expression increased in the model, without effect of therapy.

\section{DISCUSSION}

In the present animal model for flow-associated PAH, EPO treatment ameliorated pulmonary vascular remodelling and increased myocardial capillarisation. These changes were not accompanied by a decrease in pulmonary arterial pressure or by changes in right ventricular myocardial contractility.

The findings in the present model are in congruency with those in models for other forms of pulmonary hypertension. In hypoxic pulmonary hypertensive rats, right ventricular/body weight ratio and RVPs were not altered by EPO treatment, while pulmonary vascular remodelling ameliorated [6]. In mice with increased EPO production, pulmonary vasoconstrictor responses in isolated perfused lungs were decreased, as was pulmonary vascular remodelling, after a prolonged 


\begin{tabular}{|c|c|c|c|}
\hline Pulmonary arteries & CON & PAH & $\mathrm{PAH}+\mathrm{EPO}$ \\
\hline \multicolumn{4}{|l|}{ Pre-acinar $>50 \mu \mathrm{m}$} \\
\hline Number per lung section & $42 \pm 2$ & $64 \pm 7^{\circ}$ & $63 \pm 6^{*}$ \\
\hline Outer diameter $\mu \mathrm{m}$ & $130 \pm 10$ & $118 \pm 7$ & $111 \pm 6$ \\
\hline Luminal diameter $\mu \mathrm{m}$ & $111 \pm 8$ & $91 \pm 6$ & $91 \pm 6$ \\
\hline Wall thickness $\mu \mathrm{m}$ & $9 \pm 1$ & $14 \pm 1^{\circ}$ & $10 \pm 1^{+}$ \\
\hline \multicolumn{4}{|l|}{ Intra-acinar $<\mathbf{5 0} \mu \mathrm{m}^{\#}$} \\
\hline Outer diameter $\mu \mathrm{m}$ & $26.2 \pm 0.8$ & $26.8 \pm 0.6$ & $26.3 \pm 0.6$ \\
\hline Luminal diameter $\mu \mathrm{m}$ & $25.0 \pm 0.7$ & $21.8 \pm 0.7^{\circ}$ & $22.3 \pm 0.6^{\bullet}$ \\
\hline Wall thickness $\mu \mathrm{m}$ & $0.6 \pm 0.2$ & $2.5 \pm 0.2$ & $2.0 \pm 0.1^{\bullet+}+$ \\
\hline \multicolumn{4}{|l|}{ Muscularisation } \\
\hline Nonmuscularised & $87.3 \pm 3.0$ & $49.3 \pm 2.4^{\circ}$ & $51.9 \pm 2.0^{\circ}$ \\
\hline Partially muscularised & $4.8 \pm 0.9$ & $12.3 \pm 1.3^{\circ}$ & $10.2 \pm 1.1^{\circ}$ \\
\hline Totally muscularised & $7.9 \pm 2.5$ & $38.2 \pm 2.7^{\circ}$ & $37.9 \pm 1.8^{\bullet}$ \\
\hline
\end{tabular}

Data are presented as mean \pm SEM. CON: controls; PAH: pulmonary arterial hypertension experimental group; $\mathrm{PAH}+\mathrm{EPO}$ : $\mathrm{PAH}$ experimental animals treated with erythropoietin. ${ }^{\#}: \mathrm{n}=40$ per rat. ${ }^{\bullet} \mathrm{p}<0.05$ versus CON; : $p<0.05$ versus $\mathrm{PAH}$.

period of exposure to hypoxia [7, 16]. Thus, investigations in different animal models for pulmonary hypertension strongly indicate that EPO beneficially affects pulmonary vascular remodelling, without changing haemodynamics or right ventricular hypertrophy. Interestingly, EPO administration affected pulmonary vascular wall thickness, without influencing the degree of muscularisation of the smaller pulmonary vessels, indicating an effect on cellular proliferation rate rather than on composition of the vessel wall. Several mechanisms could be responsible for this reversal of pulmonary vascular remodelling. First, EPO administration leads to endothelial progenitor cell (EPC) mobilisation from the bone marrow [17, 18]. EPO stimulates EPC proliferation, adhesion and differentiation in vitro $[17,18]$. By stimulating incorporation of EPCs into the neo-endothelium, EPO facilitates endothelial repair [19]. Accordingly, EPCs might be beneficial in the repair of the damaged pulmonary endothelium in pulmonary hypertension. In the monocrotaline rat model, intravenously injected EPCs have been retrieved in the pulmonary vasculature and are shown to prevent the monocrotaline-induced pulmonary vascular remodelling [20, 21]. However, literature is not conclusive, since SAHARA et al. [22] could not demonstrate beneficial effects of injection with unfractionated bone marrow derived cells on medial wall thickness in the rat. Recently, SATOH et al. [8] demonstrated that the development of increased pulmonary pressure and of pulmonary vascular remodelling in response to hypoxia was accelerated in EPO receptor-deficient mice compared with wild-type mice. Mobilisation and recruitment to the pulmonary endothelium of EPCs were significantly impaired in these animals.

Recently, it has been suggested that the antioxidant and antiapoptotic effects of EPO are dependent on janus kinase-2 and protein kinase B (Akt) phosphorylation and may be linked with the activation of haeme oxygenase (HO)-1 [23, 24]. HO-1 is an inducible enzyme with potent antioxidant and antiapoptotic activities, which are regulated by Akt-signalling.
Decreased expression of HO-1 has been shown in human pulmonary hypertension [25], whereas the inhibition of HO-1 has been shown to aggravate murine monocrotaline-induced pulmonary hypertension [26]. Increasing HO-1 in this model is beneficial [27]. Therefore, HO-1 may have a central role in the effects of EPO in pulmonary hypertension that warrants further investigation.

Another compound that could mediate the beneficial effects of EPO administration is VEGF. Increased VEGF expression has been demonstrated specifically in the plexiform lesions of patients with PAH $[28,29]$. This may suggest a role for VEGF in the pathogenesis of the disease.

In vivo experiments have shown beneficial effects of VEGF in pulmonary hypertension. First, VEGF inhibition in newborn rats causes pulmonary hypertension [30]. Moreover, administration of human recombinant VEGF preserves endothelial function and reduces pulmonary vascular remodelling in a sheep model for primary pulmonary hypertension of the newborn [31, 32]. Gene transfer of VEGF reduced bleomycininduced pulmonary hypertension in rabbits [33] and hypoxic pulmonary hypertension in rats [34]. When VEGF-expressing vascular smooth muscle cells were delivered to monocrotalinetreated Fisher rats, RVP and right ventricular hypertrophy decreased, as did wall thickness of the pulmonary arteries [35]. EPO has been shown to induce VEGF in human vascular endothelial cells in vitro [36]. In vivo studies showed an increase in VEGF after EPO administration [37, 38]. Together, these data indicate that the beneficial effects of EPO could be mediated through a VEGF pathway.

In the present model, changes in the expression of VEGF mRNA 3 weeks after EPO administration could not be demonstrated. However, VEGF-receptor mRNA expression was altered both in the model and after EPO treatment.

VEGF-R1 is known to negatively regulate vascular formation, possibly by acting as a scavenger receptor in its soluble form $[39,40]$. In contrast, VEGF-R2 signalling is important in promoting angiogenesis [41]. In the present animal model, increased right ventricular VEGF-R1 expression suggests inhibition of VEGF-mediated vascular formation. The interpretation of the net effect of receptor regulation in the experimental lungs is more complicated, since both receptor subtypes were downregulated in the model compared with controls. Treatment with EPO probably stimulates VEGFmediated angiogenic effects, since VEGF-R1/-R2 expression ratio decreased after EPO treatment, both in the right ventricle and in the hypertensive lungs.

In the course of pulmonary hypertension, right ventricular hypertrophy and failure are important determinants of outcome. EPO treatment has been shown to improve cardiac function and to induce neovascularisation in rats with heart failure after myocardial infarction [5]. In a rat model for left ventricular hypertrophy associated with chronic renal failure, EPO treatment seemed to increase cardiac capillary density [42]. This increased vascular growth after EPO treatment has been correlated with the number of circulating EPCs [43]. Moreover, VEGF also seems to be crucial in increasing myocardial capillarisation, since bradycardia-induced myocardial angiogenesis was antagonised by blocking VEGF activity [44]. 

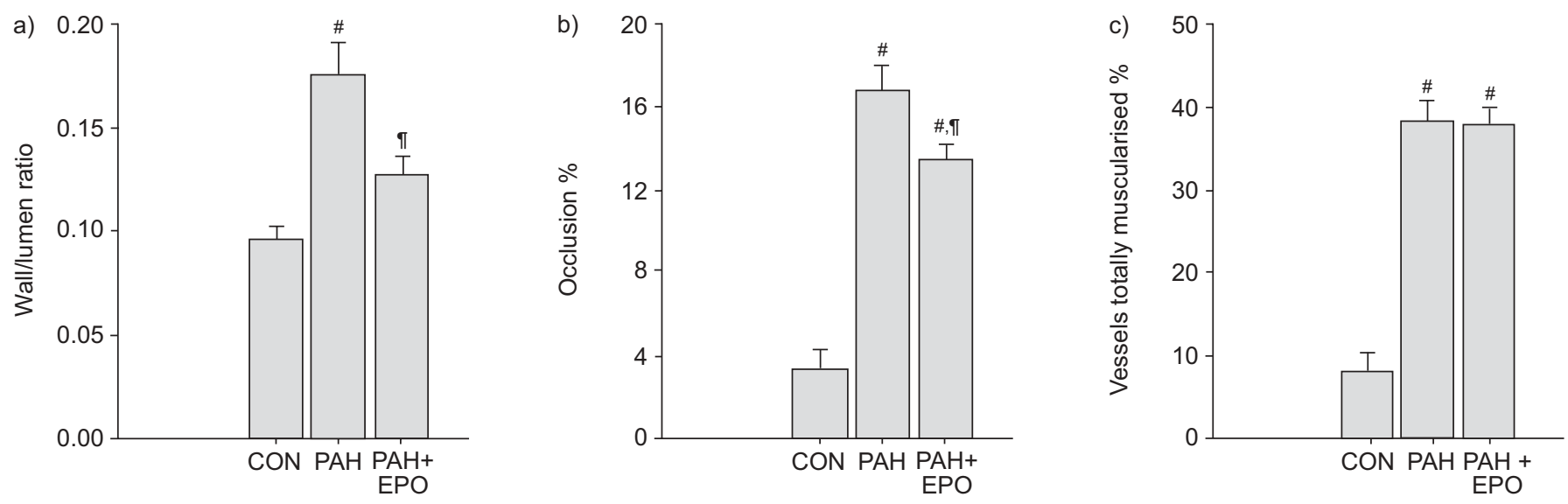

FIGURE 2. Pulmonary vascular remodelling. a) Wall/lumen ratio in the pre-acinar pulmonary arteries. b) Occlusion score of the intra-acinar pulmonary vessels. c) Percentage of the intra-acinar pulmonary vessels that was totally muscularised. Data are presented as mean \pm SEM. CON: controls; PAH: pulmonary arterial hypertension experimental group; PAH+EPO: PAH experimental animals treated with erythropoietin. ${ }^{\#}: \mathrm{p}<0.05$ versus $\mathrm{CON} ; \boldsymbol{\uparrow}: \mathrm{p}<0.05$ versus PAH.

A question remains whether EPO could play a role in the prevention of the progression of right ventricular hypertrophy to right ventricular failure in pulmonary hypertension. Although an increase in capillary density could be demonstrated in the hypertrophied right ventricle, this was not associated with an improvement in its contractility. For additional assessment of the functional consequences of the increased capillary density, the expression of different isoforms of MHC was studied. Both
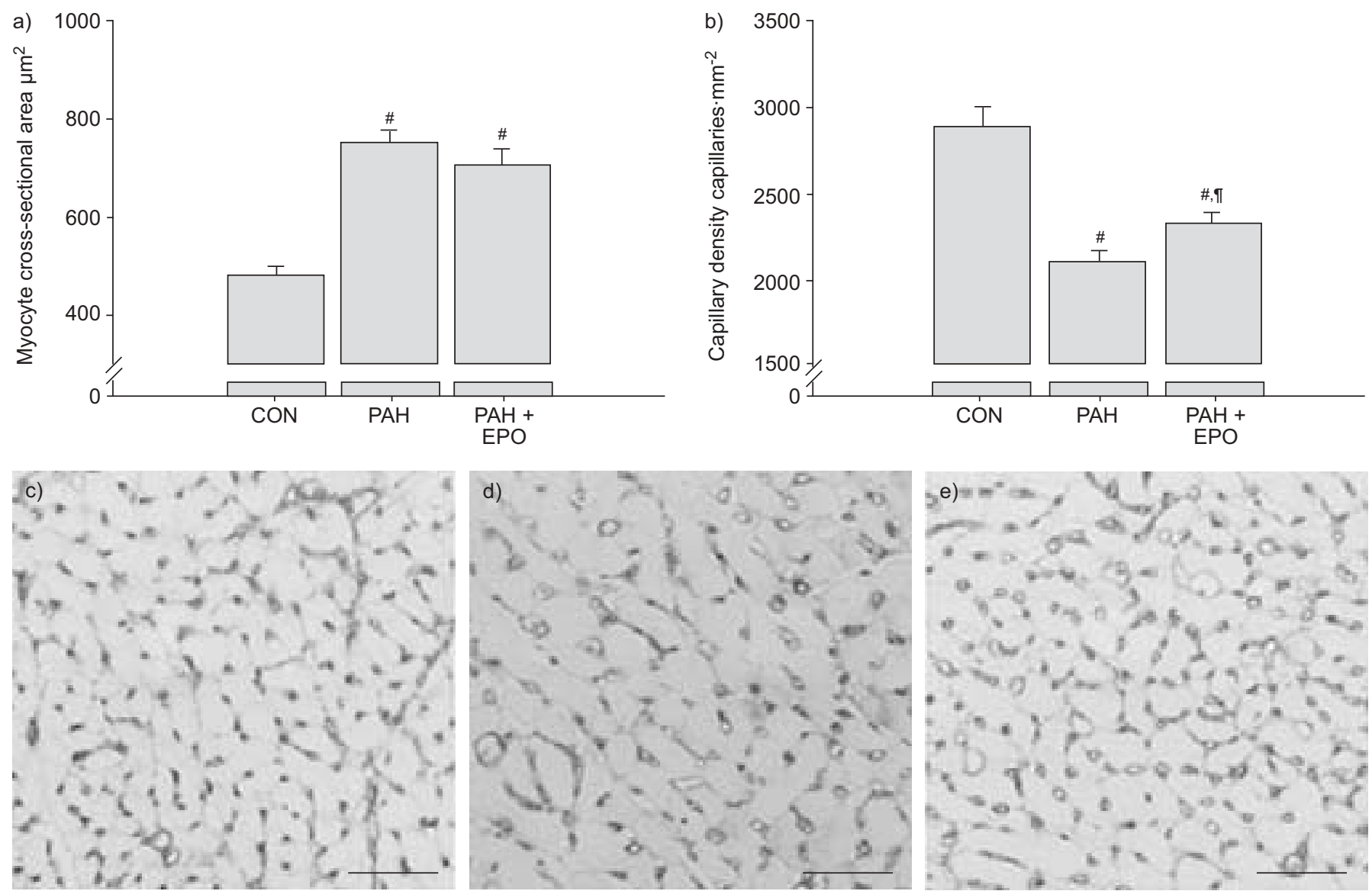

FIGURE 3. Bar graphs representing a) the myocyte cross-sectional area and b) measurements for capillary density. Data are presented as mean \pm sEM. c-e) Examples of lectin-stained tissue sections of the right ventricular wall to determine capillary density in c) controls (CON), d) pulmonary arterial hypertension experimental group (PAH) and e) PAH experimental animals treated with erythropoietin (PAH+EPO). ${ }^{\#}$ : $p<0.05$ versus control; ${ }^{\circ}$ : $p<0.05$ versus PAH. Scale bars $=40 \mu \mathrm{m}$. 

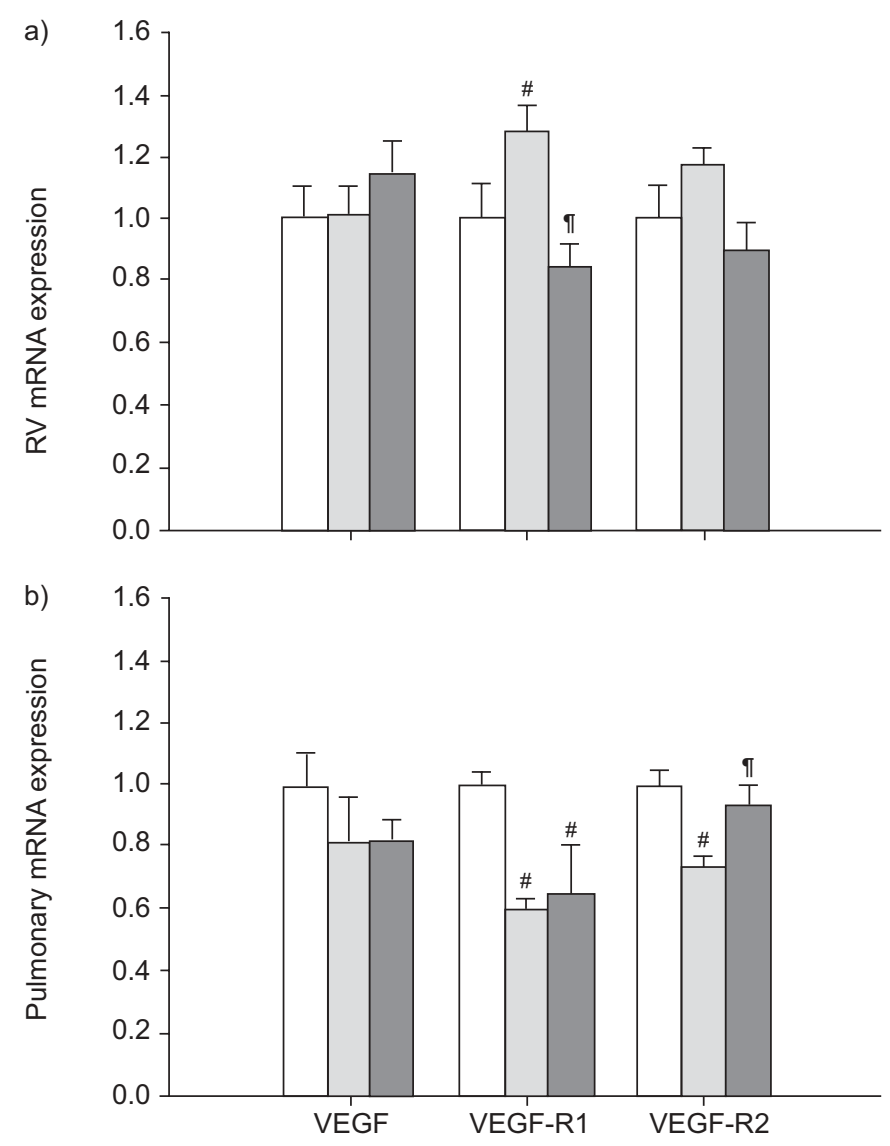

FIGURE 4. Real-time PCR for vascular endothelial growth factor (VEGF) and its type 1 (VEGF-R1) and 2 (VEGF-R2) receptors. Results are normalised as fold regulation compared with control animals in expression of the VEGF system in a) right ventricular (RV) tissue and b) pulmonary tissue. Data are presented as mean \pm SEM. $\square$ : controls (CON); $\quad$ : : pulmonary arterial hypertension (PAH) experimental group; $\square$ : PAH experimental animals treated with erythropoietin (EPO). ${ }^{\#}: p<0.05$ versus CON; ${ }^{\natural}: p<0.05$ versus PAH.

the fast $\alpha$ - and the slow $\beta$-MHC are expressed in the normal cardiomyocyte. These two forms differ in ATP-ase activity. A shift towards more $\alpha$-MHC expression is associated with improved contractility $[5,45]$. In concordance with the lack of change in contractility measurements after treatment, no differences were found in the expression of $\alpha$ - and $\beta$-MHC between treated and untreated rats.

Thus, cardiac capillarisation improved with EPO treatment, whereas this could not be associated with improved right ventricular function nor with a decrease in hypertrophy. A possible explanation for the effects observed could be the increased blood viscosity caused by EPO. Although PETIT et al. [46] initially hypothesised that EPO administration would deteriorate hypoxic pulmonary hypertension due to the associated polycythaemia, in this group's experiments pulmonary arterial pressure did not increase and pulmonary vascular remodelling appeared to be even less pronounced [6]. Moreover, isolated lungs from EPO-treated hypoxic rats had lower PVR than saline-treated hypoxic rats when perfused with blood from normocythemic donor rats [6]. This indicates that normocythemic EPO-treated animals could have decreased PVR and, consequently, less right ventricular hypertrophy. Although no significant difference was found in haematocrit 3 weeks after administration, an initial increase might have been possible [5]. The haematopoietic effects of EPO leading to an increased PVR could, therefore, counteract the beneficial structural effects on the heart.

\section{Limitations}

The present study did not allow the identification of the mechanisms through which EPO exerts its beneficial effects on cardiac and pulmonary vascular remodelling in the current model. Although haematocrit and VEGF-receptor system have been investigated 3 weeks after EPO administration, no sequential investigations were performed. Other potential mechanisms, such as activation of EPCs or induction of HO-1, were not investigated. Further studies are needed to investigate EPO's mechanisms in detail.

Furthermore, the effect of multiple doses of EPO was not addressed in the present study. The current authors chose to use a Darbepoetin dosage of $10 \mu \mathrm{g} \cdot \mathrm{kg}^{-1}$, a dosage comparable to 2,000 IU of human recombinant EPO. This dosage is a little lower than dosages used in most experiments addressing the effects of EPO in models for cardiac ischaemia and failure [5, $47,48]$. However, beneficial effects in cardiac failure were also described in much lower dosages [49]. Additionally, PRUNIER et al. [50] demonstrated mobilisation of EPCs using a dosage of $1.5 \mu \mathrm{g} \cdot \mathrm{kg}^{-1} \cdot$ week $^{-1}$.

Cardiac frequency normalised after EPO treatment but a change in pulmonary haemodynamics could not be demonstrated. If EPO treatment solely alters vascular histological parameters without having functional consequences, its clinical relevance is questionable. However, the possibility that other dosings or dosing frequencies might have led to additional benefits cannot be excluded. Secondly, only pulmonary arterial pressure was measured and not cardiac output or PVR. Since the diameter of the resistance vessels changes, it is conceivable that this affects PVR. In the present shunt model, beneficial functional effects of the reversed pulmonary vascular remodelling after EPO might have been masked by an increase in pulmonary flow after EPO, leading to unchanged pulmonary arterial pressure in the presence of reduced PVR. Possibly, the measurement of contractility, as performed in the present study, is not sensitive enough to detect more subtle changes.

In conclusion, erythropoietin causes beneficial effects on both cardiac and pulmonary vascular remodelling in a rat model for flow-associated pulmonary arterial hypertension. In the present study, no improved pulmonary haemodynamics could be demonstrated to accompany the histopathological changes. Molecular studies in the present model suggest that the vascular endothelial growth factor and its two receptor subtypes may be involved in mediating the effects of erythropoietin. These data warrant further detailed studies to investigate the mechanisms through which erythropoietin exerts its beneficial effects in pulmonary hypertension.

\section{REFERENCES}

1 Brines ML, Ghezzi P, Keenan S, et al. Erythropoietin crosses the blood-brain barrier to protect against 
experimental brain injury. Proc Natl Acad Sci USA 2000; 97: 10526-10531.

2 van der Meer P, Lipsic E, Henning RH, et al. Erythropoietin improves left ventricular function and coronary flow in an experimental model of ischemia-reperfusion injury. Eur $J$ Heart Fail 2004; 6: 853-859.

3 Parsa CJ, Matsumoto A, Kim J, et al. A novel protective effect of erythropoietin in the infarcted heart. J Clin Invest 2003; 112: 999-1007.

4 Cai Z, Semenza GL. Phosphatidylinositol-3-kinase signaling is required for erythropoietin-mediated acute protection against myocardial ischemia/reperfusion injury. Circulation 2004; 109: 2050-2053.

5 van der Meer P, Lipsic E, Henning RH, et al. Erythropoietin induces neovascularization and improves cardiac function in rats with heart failure after myocardial infarction. J Am Coll Cardiol 2005; 46: 125-133.

6 Petit RD, Warburton RR, Ou LC, Hill NS. Pulmonary vascular adaptations to augmented polycythemia during chronic hypoxia. J Appl Physiol 1995; 79: 229-235.

7 Weissmann N, Manz D, Buchspies D, et al. Congenital erythropoietin over-expression causes "anti-pulmonary hypertensive" structural and functional changes in mice, both in normoxia and hypoxia. Thromb Haemost 2005; 94: 630-638.

8 Satoh K, Kagaya Y, Nakano M, et al. Important role of endogenous erythropoietin system in recruitment of endothelial progenitor cells in hypoxia-induced pulmonary hypertension in mice. Circulation 2006; 113: 1442-1450.

9 National Research Council. Guide for the Care and Use of Laboratory Animals. 7th Edn. Washington, National Academy Press, 1996.

10 van Albada ME, Schoemaker RG, Kemna M, CrommeDijkhuis AH, van Veghel R, Berger RM. The role of increased pulmonary blood flow in pulmonary arterial hypertension. Eur Respir J 2005; 26: 487-493.

11 Rabinovitch M, Gamble W, Nadas AS, Miettinen OS, Reid L. Rat pulmonary circulation after chronic hypoxia: hemodynamic and structural features. Am J Physiol 1979; 236: H818-H827.

12 van Suylen RJ, Smits JF, Daemen MJ. Pulmonary artery remodeling differs in hypoxia- and monocrotaline-induced pulmonary hypertension. Am J Respir Crit Care Med 1998; 157: 1423-1428.

13 Van Kerckhoven R, van Veghel R, Saxena PR, Schoemaker RG. Pharmacological therapy can increase capillary density in post-infarction remodeled rat hearts. Cardiovasc Res 2004; 61: 620-629.

14 Kalkman EA, van Suylen RJ, van Dijk JP, Saxena PR, Schoemaker RG. Chronic aspirin treatment affects collagen deposition in non-infarcted myocardium during remodeling after coronary artery ligation in the rat. J Mol Cell Cardiol 1995; 27: 2483-2494.

15 Sandovici M, Henning RH, Hut RA, et al. Differential regulation of glomerular and interstitial endothelial nitric oxide synthase expression in the kidney of hibernating ground squirrel. Nitric Oxide 2004; 11: 194-200.

16 Walker BR, Resta TC, Nelin LD. Nitric oxide-dependent pulmonary vasodilation in polycythemic rats. Am J Physiol Heart Circ Physiol 2000; 279: H2382-H2389.
17 Heeschen C, Aicher A, Lehmann R, et al. Erythropoietin is a potent physiologic stimulus for endothelial progenitor cell mobilization. Blood 2003; 102: 1340-1346.

18 Bahlmann FH, DeGroot K, Duckert T, et al. Endothelial progenitor cell proliferation and differentiation is regulated by erythropoietin. Kidney Int 2003; 64: 1648-1652.

19 Urao N, Okigaki M, Yamada H, et al. Erythropoietinmobilized endothelial progenitors enhance reendothelialization via Akt-endothelial nitric oxide synthase activation and prevent neointimal hyperplasia. Circ Res 2006; 98: 1405-1413.

20 Zhao YD, Courtman DW, Deng Y, Kugathasan L, Zhang Q, Stewart DJ. Rescue of monocrotaline-induced pulmonary arterial hypertension using bone marrow-derived endothelial-like progenitor cells: efficacy of combined cell and eNOS gene therapy in established disease. Circ Res 2005; 96: 442-450.

21 Raoul W, Wagner-Ballon O, Saber G, et al. Effects of bone marrow-derived cells on monocrotaline- and hypoxiainduced pulmonary hypertension in mice. Respir Res 2007; 8: 8 .

22 Sahara M, Sata M, Morita T, Nakamura K, Hirata Y, Nagai R. Diverse contribution of bone marrow-derived cells to vascular remodeling associated with pulmonary arterial hypertension and arterial neointimal formation. Circulation 2007; 115: 509-517.

23 Calò LA, Davis PA, Piccoli A, Pessina AC. A role for heme oxygenase- 1 in the antioxidant and antiapoptotic effects of erythropoietin: the start of a good news/bad news story? Nephron Physiol 2006; 103: 107-111.

24 Smith KJ, Bleyer AJ, Little WC, Sane DC. The cardiovascular effects of erythropoietin. Cardiovasc Res 2003; 59: 538-548.

25 Achcar RO, Demura Y, Rai PR, et al. Loss of caveolin and heme oxygenase expression in severe pulmonary hypertension. Chest 2006; 129: 696-705.

26 Goto J, Ishikawa K, Kawamura K, et al. Heme oxygenase-1 reduces murine monocrotaline-induced pulmonary inflammatory responses and resultant right ventricular overload. Antioxid Redox Signal 2002; 4: 563-568.

27 Zhou H, Liu H, Porvasnik SL, et al. Heme oxygenase-1 mediates the protective effects of rapamycin in monocrotaline-induced pulmonary hypertension. Lab Invest 2006; 86: 62-71.

28 Geiger R, Berger RM, Hess J, Bogers AJ, Sharma HS, Mooi WJ. Enhanced expression of vascular endothelial growth factor in pulmonary plexogenic arteriopathy due to congenital heart disease. J Pathol 2000; 191: 202-207.

29 Hirose S, Hosoda Y, Furuya S, Otsuki T, Ikeda E. Expression of vascular endothelial growth factor and its receptors correlates closely with formation of the plexiform lesion in human pulmonary hypertension. Pathol Int 2000; 50: 472-479.

30 Le Cras TD, Markham NE, Tuder RM, Voelkel NF, Abman SH. Treatment of newborn rats with a VEGF receptor inhibitor causes pulmonary hypertension and abnormal lung structure. Am J Physiol Lung Cell Mol Physiol 2002; 283: L555-L562.

31 Grover TR, Parker TA, Markham NE, Abman SH. rhVEGF treatment preserves pulmonary vascular reactivity and structure in an experimental model of pulmonary hyper- 
tension in fetal sheep. Am J Physiol Lung Cell Mol Physiol 2005; 289: L315-L321.

32 Grover TR, Parker TA, Abman SH. Vascular endothelial growth factor improves pulmonary vascular reactivity and structure in an experimental model of chronic pulmonary hypertension in fetal sheep. Chest 2005; 128: 614S.

33 Gong F, Tang H, Lin Y, Gu W, Wang W, Kang M. Gene transfer of vascular endothelial growth factor reduces bleomycin-induced pulmonary hypertension in immature rabbits. Pediatr Int 2005; 47: 242-247.

34 Partovian C, Adnot S, Raffestin B, et al. Adenovirusmediated lung vascular endothelial growth factor overexpression protects against hypoxic pulmonary hypertension in rats. Am J Respir Cell Mol Biol 2000; 23: 762-771.

35 Campbell AI, Zhao Y, Sandhu R, Stewart DJ. Cell-based gene transfer of vascular endothelial growth factor attenuates monocrotaline-induced pulmonary hypertension. Circulation 2001; 104: 2242-2248.

36 Kertesz N, Wu J, Chen TH, Sucov HM, Wu H. The role of erythropoietin in regulating angiogenesis. Dev Biol 2004; 276: 101-110.

37 Galeano M, Altavilla D, Bitto A, et al. Recombinant human erythropoietin improves angiogenesis and wound healing in experimental burn wounds. Crit Care Med 2006; 34: 1139-1146.

38 Wang L, Zhang Z, Wang Y, Zhang R, Chopp M. Treatment of stroke with erythropoietin enhances neurogenesis and angiogenesis and improves neurological function in rats. Stroke 2004; 35: 1732-1737.

39 Hiratsuka S, Minowa O, Kuno J, Noda T, Shibuya M. Flt-1 lacking the tyrosine kinase domain is sufficient for normal development and angiogenesis in mice. Proc Natl Acad Sci USA 1998; 95: 9349-9354.

40 Fong GH, Rossant J, Gertsenstein M, Breitman ML. Role of the Flt-1 receptor tyrosine kinase in regulating the assembly of vascular endothelium. Nature $1995 ; 376$ : 66-70.
41 Shalaby F, Rossant J, Yamaguchi TP, et al. Failure of bloodisland formation and vasculogenesis in Flk-1-deficient mice. Nature 1995; 376: 62-66.

42 Amann K, Buzello M, Simonaviciene A, et al. Capillary/ myocyte mismatch in the heart in renal failure -- a role for erythropoietin? Nephrol Dial Transplant 2000; 15: 964-969.

43 Bahlmann FH, De Groot K, Spandau JM, et al. Erythropoietin regulates endothelial progenitor cells. Blood 2004; 103: 921-926.

44 Zheng W, Brown MD, Brock TA, Bjercke RJ, Tomanek RJ. Bradycardia-induced coronary angiogenesis is dependent on vascular endothelial growth factor. Circ Res 1999; 85: 192-198.

45 Herron TJ, McDonald KS. Small amounts of $\alpha$-myosin heavy chain isoform expression significantly increase power output of rat cardiac myocyte fragments. Circ Res 2002; 90: 1150-1152.

46 Petit RD, Warburton RR, Ou LC, Brinck-Johnson T, Hill NS. Exogenous erythropoietin fails to augment hypoxic pulmonary hypertension in rats. Respir Physiol 1993; 91: 271-282.

47 Bullard AJ, Govewalla P, Yellon DM. Erythropoietin protects the myocardium against reperfusion injury in vitro and in vivo. Basic Res Cardiol 2005; 100: 397-403.

48 Lipsic E, van der Meer P, Henning $\mathrm{RH}$, et al. Timing of erythropoietin treatment for cardioprotection in ischemia / reperfusion. J Cardiovasc Pharmacol 2004; 44: 473-479.

49 Lipsic E, van der Meer P, van der Harst P, et al. Low-dose erythropoietin treatment preserves cardiac function and mobilizes endothelial progenitor cells in rats with ischemic heart failure. J Am Coll Cardiol 2006; 47: Suppl. 4, 74A.

50 Prunier F, Pfister O, Hadri L, et al. Delayed erythropoietin therapy reduces post-MI cardiac remodeling only at a dose that mobilizes endothelial progenitor cells. Am J Physiol Heart Circ Physiol 2007; 292: H522-H529. 